\title{
5 Coletivos e Redes Culturais no Brasil Contemporâneo: notas sobre as relações entre cultura, economia e política na conjuntura neoliberal
}

Cultural Collectives and networks in contemporary Brazil: Notes on the relations among culture, economy and politics in the neoliberal conjuncture

Miqueli Michetti ${ }^{* *}$

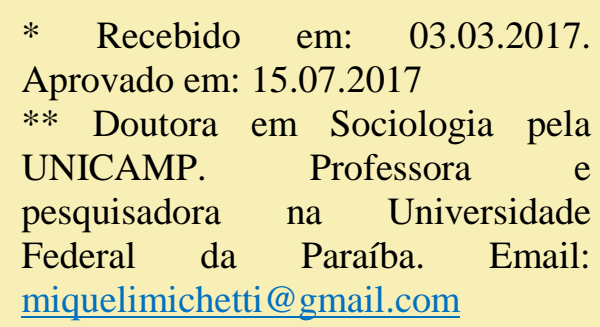

Resumo: no contexto em que a cultura é concebida como "recurso", o âmbito cultural parece incorporar práticas e discursos do mundo corporativo, o qual, de sua parte, se alimenta da legitimidade que a esfera cultural confere a tais discursos e práticas. A retórica acerca da não separação entre trabalho e lazer que o regime de acumulação flexível herdou da contracultura é (re)transposta a atividades culturais atuais na medida em que essas ideias se referem à separação histórica entre arte e trabalho que fundou as categorias "arte" e "artista". No seio dos "coletivos culturais", a fronteira entre vida pessoal e profissional é abolida e os "trabalhadores culturais" se encontram em condições precárias. $O$ funcionamento de tais coletivos parece estabelecer dinâmicas similares às experiências dos "comuns", mas assumem também a dinâmica da competição própria à "subjetividade neoliberal". No Brasil contemporâneo, essa luta visa, em grande medida, o acesso aos recursos estatais. Diante disso, tais organizações assumem características corporativas inclusive no que tange à disputa por "capital político".

Palavras-chave: Economia da Cultura; Política Cultural; Coletivos Culturais; Trabalho; Arte.
Abstract: in the context in which culture is conceived as a "resource", the cultural sphere seems to incorporate practices and discourses of the corporate world, which for its part feeds on the legitimacy that the cultural sphere confers on such discourses and practices. The rhetoric about the non-separation between work and leisure that the regime of flexible accumulation inherited from the counterculture is (re) transposed into current cultural activities insofar as these ideas refer to the historical separation between art and work that founded the categories "art" and "artist." Within organizations as "cultural collectives," the frontier between personal and professional life is abolished and "cultural workers" are in precarious conditions. In contemporary Brazil, this struggle aims, to a great extent, access to state resources. Thus, such organizations assume corporate characteristics even in the matter of the dispute for "political capital".

Keywords: Culture Economy; Cultural Policy; Cultural Collectives; Job; Art. 
1 Diferentes etapas/versões desse trabalho foram apresentadas em duas ocasiões em 2014. A primeira no XVIII ISA World Congress of Sociology, em julho de 2014, em Yokohama, no Japão, e a segunda no Seminário do Grupo de Estudos de Práticas Culturais Contemporâneas (GEPRACC), em outubro de 2014 em São Paulo. Em ambos os eventos tive ocasião de discutir o trabalho e agradeço aos colegas pela interlocução. De maneira especial, agradeço a Maria Celeste Mira, Ana Lúcia de Castro e Edson Farias pelos comentários e sugestões.

\section{Introdução}

O presente texto ${ }^{1}$ analisa o surgimento e a atuação de coletivos e redes culturais no Brasil contemporâneo tendo por pano de fundo a situação da cultura no contexto do regime de acumulação flexível de matiz neoliberal. Com o objetivo mais amplo de compreender sociologicamente algumas relações atuais entre cultura, economia e política, buscou-se ir além dos debates mais circunstanciais acerca do funcionamento dos coletivos de cultura específicos. Entretanto, o caso do Fora do Eixo, coletivo que recentemente ganhou proeminência no país, será o exemplo mais evocado por ser considerado heurístico. Não se trata, porém, de um escrito sobre esse coletivo em particular. O intuito é dar a ver como a situação material e simbólica da cultura nos dias atuais cria condições para o surgimento de novas formas de organização das atividades culturais, as quais (co)respondem a contradições levantadas pelo posicionamento do Estado e do Mercado no que diz respeito à cultura. Ao mesmo tempo em que eles se apresentam como resposta a essas contradições, eles tendem a reproduzi-las e a levantar novas tensões.

Em termos metodológicos, o trabalho tem fundamento mais teórico que empírico. Porém, como esses âmbitos se retroalimentam nas pesquisas em Ciências Sociais, as reflexões teóricas foram estimuladas pela convivência e conversas com pessoas que trabalham com cultura no Brasil, algumas delas membros de coletivos, e que enfrentam as dificuldades que, na conjuntura atual, se apresentam a essa esfera. Além disso, como se trata de um fenômeno recente e em andamento, e como o tema tem gerado discussões acaloradas, o material disponível na Internet sobre os coletivos e redes é bastante extenso e pode ser usado ora como fonte de informação, ora como material sobre o qual se debruçar com vistas à análise de discurso. Ademais, trabalhos acadêmicos têm sido realizados sobre o funcionamento detalhado de determinados coletivos. Esses trabalhos nos foram úteis e estão discriminados nas notas e nas referências, assim como os principais websites utilizados.

$\mathrm{O}$ roteiro do artigo resultante desse estudo exploratório se inicia com uma breve exposição sobre a construção histórica da arte como antítese do trabalho, passa por uma explanação acerca da situação mais geral da cultura no regime de acumulação flexível, perpassa as condições de emergência dos chamados "novos modelos de negócios culturais" na atual conjuntura, com atenção especial aos EUA, e desemboca na emergência dos coletivos no Brasil, atentando aos aspectos políticos e econômicos implicados em seu surgimento e atuação. Algumas considerações de ordem teórica encerram o texto.

\section{A construção histórica da arte como antítese do \\ trabalho}

A distinção entre arte e trabalho, entre artista e artesão, remonta há séculos e é bastante conhecida (GOMBRICH, 2012; 
WARNKE, 2001; GAY, 2009, entre outros). A arte, para ser Arte, precisou ser acreditada enquanto alheia à esfera comezinha do trabalho. A figura histórica do artista só pôde afirmar-se ao declararse liberta das necessidades objetivas. A arte busca, portanto, se distanciar do reino econômico.

Atividade de "amadores", a arte pretende ser o oposto do dinheiro. O dinheiro é o equivalente universal e só funciona como tal na medida em que abstrai a diferença de tudo o que existe. Já a arte, por definição, não pode ser intercambiável. Uma obra não pode ser "equivalente" a outra obra. No mesmo sentido, o artista é construído historicamente como o oposto do homem comum, de cujos interesses e necessidades ordinários, em princípio, não partilha. Logo, a legitimação mesma da categoria artista implica em que a atividade artística não possa ser remunerada da mesma maneira que o trabalho. Aliás, boa parte da história da arte ocidental narra o apagamento dos traços do esforço/trabalho do realizador artístico. Se a modernidade traz o trabalho mensurável em unidades de tempo (MARX, 2013), ela traz também seu oposto antitético, a construção social da arte enquanto Arte, e do artista enquanto o antípoda do trabalhado comum. Em termos sociológicos, a análise de Bourdieu (1996) sobre a formação e autonomização do campo artístico são esclarecedoras a esse respeito.

No entanto, a história da arte é acompanhada pela história do financiamento da arte, pois ela não prescinde de condições objetivas para existir, de maneira que sempre existem vínculos (ora mais ora menos mediados) com o poder político e/ou econômico. E, se por um lado, a arte precisa de condições materiais para ser viável, por outro, ela pode ser transformada em dinheiro. A arte pode ser um "alvo de investimento", um meio de multiplicar capital (MOULIN, 2003, THOMPSON, 2012). Tal obviedade, entretanto, deve manterse velada, pois a produção artística que se propõe venal não pode ser considerada boa arte.

Esses nós históricos e lógicos nas relações entre arte e trabalho ou, ainda, entre arte e dinheiro e, em sentido mais amplo, entre cultura e economia, nos conduzem à nossa questão fundamental, que porta sobre as ligações entre cultura, economia e política à época do chamado regime de acumulação flexível (HARVEY, 1989).

Antes de nos debruçarmos mais especificamente sobre o caráter contemporâneo dessas conexões, é preciso que fique claro que arte e cultura não são consideradas aqui como sinônimos ou equivalentes. Sabemos que o termo cultura é polissêmico, podendo designar desde um quadro de Velásquez até o hábito de fazer a sesta após o almoço, para ficarmos só com o exemplo espanhol. Sobre essa dificuldade de se utilizar com rigor a noção, Terry Eagleton (2005, p.51) afirma que o sentido estético de cultura, ligado às artes, seria demasiadamente restrito, ao passo que o significado antropológico do termo, designando modo de vida, seria amplo 
demais. As análises de Fredric Jameson (1996) sobre a imbricação contemporânea entre cultura e economia podem superar esse impasse terminológico e conceitual, na medida em que elas apontam uma "explosão" da cultura no mundo contemporâneo que permitiria conjugar ambas as acepções. $\mathrm{O}$ argumento do autor sobre a imbricação entre cultura e economia parece válido para se conceber as atuais relações entre criação cultural e regime de acumulação flexível, tal como elas têm se dado nos chamados "novos modelos de negócios culturais", no seio dos quais atividade artística, empreendedorismo, modos alternativos de organização da vida cotidiana e ativismo político se mesclam e se confundem.

\section{Cultura e regime de acumulação flexível}

As relações entre cultura e economia ganham novas inflexões a partir de meados da década de 1970. Com a crise do "regime de acumulação fordista", entra em cena o chamado "capital imaterial" (GORZ, 2005). As atividades do espírito são transformadas no fundamento de empreendimentos econômico-culturais, uma vez que o principal "ativo" da economia passa a ser o conhecimento, a informação, a criatividade, a cultura...

As críticas que a contracultura estabeleceu ao "modo de vida total" fordista acabaram por se tornar a base do chamado "regime de acumulação flexível" (HARVEY, 1989) ou do "novo espírito do capitalismo" (BOLTANSKI e CHIAPELLO, 2011). As críticas à sociedade disciplinar, à burocracia, à hierarquia, à autoridade e à especialização na esfera do trabalho foram combustíveis para a reorganização flexível do trabalho com seus novos modos de controle, baseados na internalização do sentido e da "motivação", no trabalho em equipe, no dito "flexitempo", nas ideias de multitarefas, de "mobilização total” e de autocontrole. As habilidades pessoais são vistas como parte do "capital humano", a capacidade de estabelecer vínculos de confiança são uma das faces do controle do trabalho e a separação entre tempo de vida e tempo de trabalho se esvanece.

De acordo com a teoria do "capital humano", preconizada pela Escola de Chicago como o oposto ao "funcionário" fordista (LOPEZ-RUIZ, 2006), o trabalhador flexível se porta como empresário de si mesmo. Ele seria responsável por sua própria empregabilidade, ou seja, pela venda de seu capital humano (não mais força de trabalho) à esfera empresarial. Vida pessoal e vida profissional se misturam. Habilidades técnicas e disposições sociaisculturais se mesclam. Capital e trabalho se confundem nas duas pontas da pirâmide social, proclamada desde então como "rede". Trabalhadores recebem, ao invés de salários fixos, participação nos lucros ou stock options - seus interesses também estão na alta das ações, no bom andamento da bolsa de valores. Ou trabalhadores devem se incumbir de criar seu próprio emprego. Também na esfera da cultura, essa época equivale à chamada "pejotização" da atividade. Prestadores de serviços culturais são incumbidos de seus 
próprios encargos, ao mesmo tempo como patrões e empregados de si mesmos.

Na esfera do consumo, das críticas à homogeneidade e à massificação das décadas fordistas emergem as concepções de consumo individualizado, expressivo, "de experiências", enfim, o consumo dos nossos dias (ANDRADE, 2011). As relações humanas são transformadas em commodities nesse novo formato de consumo. Na medida em que, com a financeirização ampliada das corporações, o capital fixo será visto como despesa operacional, o valor das empresas passa a ser dado pelo seu potencial de lucro futuro. Assim, é crucial garantir vínculos de longo prazo com os clientes. Se eles são parte da produção do valor, controlá-los passa a ser tão necessário quanto controlar o trabalho (RIFKIN, 2000). Além disso, na época em que "trabalhar é produzir-se", o consumo passa a ser visto como investimento em si mesmo (GORZ, 2005). Tudo isso passa pela mobilização da esfera cultural.

É preciso lembrar ainda que a partir do último quarto do século $\mathrm{XX}$, a tecnologia ganha papel preponderante no regime de acumulação e na organização social. No momento histórico de reforma do modo de produção capitalista, ela é vista como um meio para substituir mão-de-obra, sobretudo após a crise do controle do trabalho vivida de finais da década de 1960 a meados da de 1970. Ela se torna também um setor aquecido da economia e, como alvo de investimentos, servirá de combustível à retomada do crescimento econômico. Ela se liga à saída de crise econômica também na medida em que possibilita a globalização do mercado financeiro, que, após a queda do acordo de Bretton Woods, se expandirá de maneira inédita pelo planeta. Logo, a tecnologia liga-se ao capitalismo neoliberal financeirizado tanto por permitir a interligação mundial das bolsas de valores e de outras instituições financeiras quanto por deslocar os trabalhadores das atividades produtivas, substituindo-os. Os arautos da nova era proclamaram a emergência da "sociedade da informação", da sociedade pós- industrial, da sociedade em rede, do "capitalismo cognitivo", da "economia criativa".

As carreiras ligadas à produção de conteúdo e gestão de informações soam então promissoras. É nesse setor que surgem as empresas arquetípicas do regime de acumulação flexível. Não por acaso, elas ecoam a partir da costa oeste americana, berço da contracultura. Segundo a interpretação de Löwy (2008), o capitalismo contemporâneo teria incorporado a face cultural das críticas ao mundo fordista de modo a neutralizar a face social e política do fenômeno. Como apontado acima, Boltanski e Chiapello (2011) indicam que o capitalismo é inclusive alimentado pela crítica.

Com a criação da rede mundial de computadores, a Internet, muito foi dito sobre a possibilidade de democratização da produção e do acesso à cultura. Ouvia-se que todo mundo poderia tanto criar como disponibilizar conteúdos culturais na rede, e isso tudo 
gratuitamente (NICOLAU NETTO, 2010). Diante disso, a produção e o consumo cultural se misturam; o produtor e o usuário se confundem. $\mathrm{O}$ trabalho e o lazer se dão ao mesmo tempo, na mesma plataforma. Além disso, os produtores de conteúdo artístico-cultural já não são alijados de seus "meios de produção", pois a partir do final do século $\mathrm{XX}$, computadores pessoais e outros aparelhos conectáveis se disseminam.

Não obstante, se muitos têm a possibilidade de produzir cultura, são as agências/empresas que concentram e organizam os acessos as que, de maneira geral, conseguem monetizar-se na Internet. Quando tudo aparece como gratuito, é a maior parte do trabalho cultural que, de fato, o será. Ao produtor de conteúdo quase nada cabe do imenso latifúndio da Internet, cujo lucro é majoritariamente rateado entre megaempresas como Google, Facebook, que arrendam seu espaço para fazer publicidade de outras empresas ou sabem dizer a elas quem são e onde estão seus consumidores-alvo. Contam para isso com a atuação dos próprios usuários, que são, em última instância, o fundamento da valorização dos gigantes da Internet. Logo, esta se configura como um espaço de diversificação e controle, de dispersão e concentração de poder simbólico e econômico. Trata-se de uma metonímia da sociedade de configuração neoliberal (NICOLAU NETTO, 2012). E, no entanto, ela é comumente concebida o veículo da maior "democratização" da produção e do consumo culturais.
Com isso - somando-se o fato de que ocorre no final do século XX uma alteração na estrutura ocupacional da indústria para a área de serviços, culturais inclusive - , boa parte da geração que acreditou no canto de sereia da "sociedade da informação" e formouse em profissões a ela relacionadas, encontra-se atualmente escrevendo, fotografando, filmando, compondo, tocando de graça, na esperança de "fazer o nome circular pela rede" para então monetizar sua atividade. As dinâmicas de funcionamento das grandes empresas da Internet trazem consigo uma retórica que ultrapassa a rede, dizendo respeito a toda uma geração de criadores de cultura que, ao mesmo tempo em que produzem muito do conteúdo que sustenta a rede, não encontra nela meios para sustentar-se.

\section{Os novos modelos de negócios culturais}

Evocado em várias acepções e com diferentes intenções políticas, o termo neoliberalismo pode mais confundir que esclarecer. Por isso, é interessante lembrar, ainda que de maneira breve e bastante simplificada, que ele designa

a) uma doutrina política que prevê que o Estado, como outros agentes coletivos, devem se restringir a garantir a atuação econômica de agentes privados individuais. Atente-se para que, nessa concepção, tanto pessoas quanto empresas são consideradas como indivíduos, donde haver pessoas físicas e pessoas jurídicas. Isso nos leva à sua acepção como 
b) doutrina econômica, que imagina que a melhor maneira de garantir a eficiência é a concorrência;

c) A concepção de sociedade que fundamenta esse ideário é a de que ela é um aglomerado de indivíduos racionais competindo entre si por recursos escassos. Margareth Thatcher foi categórica ao anunciar que "não existe sociedade, o que existe são indivíduos e suas famílias";

d) Também a subjetividade correlata a essa sociedade concebida em termos darwinistas seria calcada no princípio da concorrência;

e) Embora conte com ideólogos que a enunciam, essas premissas não são um a priori do neoliberalismo. Ao contrário, ele se realiza como processo histórico, em geral de maneira incoerente com boa parte das diretrizes previstas em seus “documentos de intenção" (HARVEY, 2008).

Tendo isso em mente, empregamos o termo neoliberalismo como uma caracterização condensada das relações que se estabelecem entre Estado, capital e sociedade/trabalho a partir de finais da década de 1970 e tendo por pano de fundo os princípios delineados acima.

Ainda mais contundentemente que as inferências derivadas das premissas, a observação de sua concretude histórica permite perceber que o neoliberalismo impulsiona o individualismo, o princípio da competição, o medo permanente da eliminação (GORZ,
1999; CASTEL, 1998; BOURDIEU, 1998). Ao mesmo tempo, contudo, o mundo do "the winner takes all" e do "cada um por si e contra todos os outros" traz consigo tentativas de sobrevivência dos que sentem que, sozinhos, têm poucas chances de sobrevivência. As dinâmicas de concorrência exacerbada acabam por condicionar a criação de modelos de organização coletiva de diversas atividades, entre elas a atividade cultural.

É nesse contexto que surgem os "coletivos criativos", os "coletivos culturais", as "redes de colaboração" e os chamados "novos modelos de negócios culturais". Neles, o processo de incorporação da contracultura pelo capitalismo flexível parece percorrer o caminho na outra via. A cultura passa a incorporar práticas e discursos próprios à acumulação flexível, que, de sua parte, formou-se embebida no caldo da contracultura. Assistimos hoje à imbricação entre formas de organização corporativa típicas ao regime de acumulação flexível e formas aparentemente alternativas de organização da cultura.

Os chamados "novos modelos de negócios culturais" dizem respeito especialmente às chamadas "start ups da indústria tech", mais características da economia estadunidense que, nas últimas décadas, deu lugar a investimentos pesados em tecnologia. Em um texto sobre a nova geração de empreendedores do mundo tecnológico, Nathan Heller (2014) precisa que "hoje em dia, a indústria tech tem a ver com tudo que envolve computadores, 
http://www.huffingtonpost.com/mic helle-miller/introducing-themuppie_b_5155296.html. internet, meios de comunicação digitais, redes sociais, smartphones, dados eletrônicos, crowdfunding e, de um modo geral, a criação de novos modelos de negócios. Ou seja: em determinado momento, o tech deixou de ser uma simples indústria e se transformou no substrato da maioria das coisas que vêm transformando a cultura urbana”. Com isso, esses novos modelos se referem também aos "coletivos criativos" e aos "coletivos de cultura". Eles enunciam princípios da chamada "economia colaborativa", da "economia solidária", do "associativismo" e do "cooperativismo". Ao mesmo tempo, dão lugar a relações econômicas características do regime de acumulação flexível: organização horizontal, trabalho em rede, tempo flexível, captação de recursos, multitasking, hotdesking, monetizing... O léxico compartilhado indica uma isomorfia de práticas e discursos.

Na costa Oeste estadunidense, as condições de possibilidade de tais empresas e coletivos radicam no fato de que eles se ligam a grandes empresas de tecnologia de informação e comunicação. São vizinhos da Google, da Yahoo, da Apple. Seus membros oscilam entre as funções de empreendedores e de contratados das maiores empresas do setor, frequentemente combinando-as (HELLER, 2014). Além disso, eles costumam ser financiados por investidores em busca de boas opções de investimento de risco, especialmente depois da crise financeira de 2008.

$\mathrm{Na}$ época em que o capital se reproduz sem lastro, o setor de tecnologia, cuja valorização é variável e flexível, será um alvo privilegiado de investimentos. A arte também serve a esse propósito, uma vez que seu valor monetário também pode ser especulado (FREDERICO, 2013). Não é por coincidência, portanto, que no seio desses empreendimentos, tecnologia e arte se fazem juntas. Um mesmo jovem pode possuir um cartão de visitas de "colaborador" de uma grande empresa de tecnologia, outro de artista plástico e ainda um de marchand ou de sócio de galeria de arte. "É a vida dos três cartões de visita" (HELLER, 2014) vivida pela geração apelidada de "muppies", cujo ethos ainda está por ser investigado em minúcias. Com isso, não queremos dizer que os produtores de cultura dos EUA não vivam sob condições de precariedade, mas apontar, por comparação, que, apesar de existirem aspectos comuns, a situação em que surgem difere das condições de emergência e existência dos coletivos no Brasil. Embora determinados discursos se assemelhem no mundo todo e as dinâmicas próprias ao regime de acumulação flexível de matiz neoliberal vicejem em todo o planeta, as práticas se realizam de maneiras distintas a depender de diferentes condições de possibilidade de tais práticas ao redor do globo.

\section{A emergência dos coletivos no Brasil: aspectos políticos}

\section{e econômicos}

Pensar o Brasil a partir da perspectiva analítica calcada apenas no Estado-nação é despropositado. O país se insere na 
economia global e isso não é novidade nem em termos históricos nem em termos analíticos. Ao menos desde Caio Prado Jr (1991), nos idos dos anos 1940, aprendemos a ver o Brasil como parte da economia capitalista mundial. Contudo, como apontam Renato Ortiz (1994) e Octavio Ianni (2006), a globalização contemporânea é ao mesmo tempo una e diversa. Ela se realiza distinta e desigualmente no espaço. Assim, embora o Brasil seja parte da economia global, o capitalismo guarda especificidades no país e é na medida dessas especificidades que se dá sua inserção global.

As transformações econômicas e sociais que ocorreram recentemente no Brasil são inegáveis. Desde o início dos anos 2000 , a partir de um "pacto conservador" e de uma conjuntura mundial favorável, a implantação de políticas de transferência de renda, o aumento real do salário mínimo e a expansão do acesso ao crédito deram condições para a ascensão de milhões de pessoas ao consumo (SINGER, 2012; FREDERICO, 2013).

Além disso, como as transformações sociais no Brasil têm sido realizadas sob a bandeira da inclusão via consumo, o país assistiu à emergência de condições políticas, econômicas e jurídicas que estimularam os mercados de cultura. Boa parte das políticas culturais no Brasil tem consistido em políticas econômicas. Nos últimos dez anos, agentes estatais (empresas estatais, fundações, ministérios, bancos, institutos, universidades, agências reguladoras, agências de desenvolvimento regional, serviços de apoio ao empreendedorismo, entre outros) têm criado, direta e indiretamente, as condições para o desenvolvimento de mercados de cultura. Exigências legais, como no caso do Fundo Setorial do Audiovisual e da Lei 12.485, chamada de lei da TV por assinatura, impulsionam empresas de cultura; políticas da Secretaria da Economia Criativa financiam a consecução de micro e pequenos empreendimentos de cultura; e iniciativas como o Vale Cultura fomentam um expressivo contingente de novos consumidores culturais. Em direção convergente, os bens e os serviços culturais passam a ser concebidos como vetores de desenvolvimento local e regional. No âmbito das políticas, portanto, a cultura é incentivada enquanto tecnologia social e setor econômico. Entretanto, se por um lado assistimos a investimentos recentes no mercado de cultura por parte do poder público no Brasil, por outro lado parece permanecer válido o diagnóstico traçado por Francisco de Oliveira em 2003, no início da chamada "Era Lula". Para Oliveira, o país não teria realizado a revolução digital-molecular, ou seja, estaria alijado das possibilidades de "acompanhar" o capitalismo contemporâneo a não ser como fornecedor mundial de matérias-primas e commodities por meio do latifúndio e da monocultura, fenômeno que atende recentemente pelo nome de "agronegócio".

Logo, as condições para os coletivos são diferentes por aqui. $\mathrm{Na}$ ausência de um casamento entre tecnologia, finanças e arte/cultura, os "novos modelos de negócios culturais" no Brasi 
Mais informações disponíveis em http://www2.cultura.gov.br/site/categori a/apoio-a- projetos/mecanismos-deapoio-do-minc/lei-rouanet-mecanismosde-apoio-do-minc-apoio-a-projetos/.

Acesso em 03/05/2014.

Para mais informações consultar o website da instituição: http://foradoeixo.org.br/ . Para análises http.//Roradocixo.org.br/ . Para análises sobre o sungineno e o funcionanento da entidade consultar SAVAZONI, Rodrigo Tarchiani. Redes políticoculturais e ativismo digital: o caso do circuito Fora do Eixo. [dissertação de mestrado - Universidade Federal do $\mathrm{ABC}], 2013$ e FONSECA, André Azevedo da. O valor do "egocard": afetividade e violência simbólica na rede Fora do Eixo. Revista FAMECOS. Porto Alegre, v. 22, n. 1, p. 94-119, jan-mar. 2015

Como exemplo de como isso tem ocorrido, podemos evocar a resposta do FdE ao que considera "críticas caluniosas" acerca de sua aproximação com o Ministério da Cultura. A entidade nega que recebera recursos do $\mathrm{MinC}$, ao mesmo tempo em que reafirma tomar parte do debate sobre políticas públicas. Nas palavras do coletivo: "Já anunciamos publicamente e reforçan anunciamos publicamente e reforçamos paricipar de nera do Eixo não irá participar de nenhum edital e nem usufruir de nenhum recurso oriundo do Ministério da Cultura. Abdicamos completamente de disputar os recursos e editais, mas não abrimos mão da participaçãosocial e dos debates sobre as políticas públicas. Acreditamos ser fundamental uma política sólida para

dependem com frequência de recursos públicos para atuarem. Boa parte desses recursos é oriunda de "editais" de órgãos públicos e/ou de uma política de incentivos fiscais que possibilita que pessoas físicas e jurídicas apliquem parte do imposto de renda devido em "ações culturais", conhecida como "Lei Rouanet". Diferentes instâncias culturais disputam esses recursos, e empresas de cultura, coletivos e artistas individuais contarão com capitais desiguais nessa luta concorrencial.

Os artistas que são capazes de atrair mais olhares sairão na frente na disputa pelos impostos transferidos por empresas via Lei Rouanet, já que elas buscam antes de tudo um veículo de publicidade. Nesse sentido, é dado aos departamentos de marketing de grandes empresas o papel de gestores culturais públicos. Em sentido semelhante, se determinado coletivo consegue acumular considerável capital social e político, é mais provável que ele seja mais bem sucedido no acesso aos editais públicos. The winner takes all: a lógica neoliberal de concentração de poder material e simbólico tende a se reproduzir também na relação com as instâncias públicas (DARDOT e LAVAL, 2009). Diante disso, alguns coletivos buscam se aproximar da esfera governamental.

Por se apresentar atualmente como o coletivo mais importante em atuação no país, o "circuito de coletivos Fora do Eixo" ${ }^{4}$ pode ser tomado como exemplo heurístico de como esse fenômeno tem ocorrido no Brasil contemporâneo ${ }^{5}$. A entidade surge nos anos 2000 como resposta à crise da indústria fonográfica no país, com o foco inicial na organização de festivais de música que dinamizassem regiões fora do eixo Rio-São Paulo, donde o nome da organização. Sob Lula, quando Gilberto Gil assume o Ministério da Cultura, o FdE ganha influência nas discussões sobre política cultural no país, o que se estende às gestões de Juca Ferreira à frente do MinC, influência que também manifestou-se no período em que este foi secretário de cultura da cidade de São Paulo, no início da gestão de Fernando Haddad. As ligações da instituição com o Partido dos Trabalhadores é inegável, embora em seu seio se afirme que

As Políticas Públicas não são partidárias. Não acreditamos em política de governo, acreditamo em políticas de estado. O Estado não é o PT muito menos o PSDB! Alguns partidos estão abertos ao diálogo e outros não, mas as políticas públicas independem deles ${ }^{6}$.

No que tange às receitas da entidade, além da captação de recursos via leis de incentivo, o FdE receberia verbas públicas de dezenas de prefeituras e também de governos estaduais comandados por diversos partidos, desde o PT até o $\mathrm{PSDB}^{7}$. Ao ser indagado sobre as ligações com o MinC no início da segunda gestão de Juca Ferreira, em janeiro de 2015, Pablo Capilé, fundador e "líder" do FdE, no mesmo enunciado em que nega participação formal nos quadros do ministério, afirma, buscando ressaltar a importância da "rede cultural" que lidera, que

Redes como o Fora do Eixo são laboratórios de

Dossiê Práticas e Políticas Culturais: Paradoxos e diálogos com a tecnologia

Arquivos do CMD, Volume 5, N.1. Jan/Jul 2017 
que possam fazer frente ao conglomerado de comunicação corporativa instalado no Brasil, esse sim, nosso inimigo comum." Disponível em http://foradoeixo.org.br/2015/05/12/ quem-tem-medo-de-politica-

publical. Acesso em 12/06/2015. Grifos nossos). Aliás, as "notas oficiais" do website da instituição, consistem, de maneira geral, a responder a críticas e acusações semelhantes e podem ser tomadas como sintomáticas das novas relações entre "novos negócios culturais" e políticas públicas no Brasil contemporâneo. A título de exemplo, consultar http://foradoeixo.org.br/category/not as-oficiais/

http://foradoeixo.org.br/2015/03/03/ calunia-requentada/. Acesso em $12 / 06 / 2015$

Ministério da Cultura autorizou Fora do Eixo a captar R\$ 8,8 milhões desde 2009. Por Ricardo Galhardo iG São Paulo | 12/08/2013. Disponível em http://ultimosegundo.ig.com.br/politi ca/2013-08-12/ministerio- dacultura-autorizou-fora-do-eixo-acaptar-r-88-milhoes-desde-

2009.html. Acesso em 17/06/2015. ${ }^{8}$ FORA do Eixo, dentro do MinC. Folha de São Paulo, Ilustrada, 12 de janeiro de 2015.

Entrevista de Giselle Beiguelman originalmente publicada na revista políticas públicas e tecnologias sociais, [que] vieram para ficar, como o MST, o MTST, o movimentos de mídia livre, os Pontos de Cultura. Vejo como um avanço, a possibilidade dos movimentos atuarem por dentro e por fora do Estado $^{8}$.

Ao mesmo tempo, a formação discursiva característica da época neoliberal no que diz respeito à atuação do Estado enforma o discurso da instituição. Contudo, como a "rede" depende de recursos públicos em termos simbólicos e econômicos, tal formação discursiva simultaneamente se distingue e se aproxima da retórica neoliberal. Assim, no mesmo movimento retórico em que são atribuídas tarefas ao Estado, especialmente no que concerne a "bens públicos" (STREECK, 2013), como a cultura, ele é criticado em seu "desempenho", em sua "eficiência", o que justificaria sua substituição seja por empresas, seja por organizações sociais. Nas palavras de Capilé:

Muito do que fazemos quem deveria fazer é Estado. Criar um circuito de festivais, criar um circuito de música independente, levar o cara de Amapá, do Rio Branco, de Cuiabá para tocar pelo Brasil, pensar um fluxo de distribuição..., quem deveria estar fazendo isso é a Funarte, o Minc, que, vale lembrar, têm bem mais recursos do que nós para fazer tudo isso e não conseguem fazer metade do que a gente faz ${ }^{9}$.

Nosso objetivo não é escrutinar a atuação de um coletivo especificamente, mas esclarecer que, se de uma parte as políticas culturais revelam-se em grande parte políticas econômicas, de outra parte alguns dos novos agentes econômico-culturais buscam operar também como agentes políticos. Sobre isso, ao analisar o que chama de estruturas sociais da economia, Pierre Bourdieu destaca que

[...] as lutas para transformar ou conservar as representações legítimas que, uma vez investidas da eficiência simbólica e prática do regulamento oficial, são capazes de comandar realmente as práticas, são uma das dimensões fundamentai das lutas políticas pelo poder estatal $(2000$ p.116)

Sob a retórica do ativismo político, do movimento socia autônomo, da juventude participativa, o FdE se valoriza por possuir capital político de mobilização. A política torna-se moeda de troca na luta concorrencial por recursos escassos que marca a cultura no regime de acumulação flexível em sua variante brasileira.

Entretanto, na época do questionamento do Estado e da deslegitimação da política institucional, coletivos e redes culturais buscarão assumir a "governança" de bens e serviços públicos, comuns ou políticos, como a cultura. Às vezes por princípio, mas mais frequentemente via crítica à performance estatal, os coletivos buscarão atuar de forma semelhante à maneira como vêm atuando empresas, fundações e ONGs no que diz respeito à sua pretensão de cumprir o que foi concebido em dado momento histórico como pape do Estado.

Isso nos leva da face política à face econômica de tais redes e 
Select em 19 de agosto de 2013. Disponível http://www.canalcontemporaneo.art. br/brasa/archives/005669.html>Aces so em 16/06/2015 coletivos, na medida em que esses "novos modelos de negócios culturais" dão lugar a relações econômicas típicas do regime de acumulação flexível. Ao mesmo tempo em que sua dinâmica de funcionamento depende do Estado, sua atuação se dá nos termos do "novo empreendedorismo", que funde a retórica da flexibilidade e da criatividade com os princípios da chamada "economia colaborativa".

O fundamento mais concreto disso, no que diz respeito ao Brasil contemporâneo, deve ser procurado em duas constelações distintas, mas correlatas, da estrutura social. Quando a dita "nova classe média", melhor designada como "batalhadores" (SOUZA, 2012), galga um novo lugar na sociedade brasileira mais como consumidora do que como cidadã, surgem as condições materiais para o exército de "infoproletários" (ANTUNES; BRAGA, 2009) ou "batalhadores do telemarketing" (SOUZA, 2012). Ao mesmo tempo, mas em outro ponto da constelação de precarização trazida pelo neoliberalismo, a "antiga classe média", que historicamente tinha sua condição de classe garantida pela posse de capital cultural e capital escolar materializado em diplomas (BOURDIEU; PASSERON 1992) se avalia como decadente.

Diante disso, por um lado, o processo que Robert Castel (1998, p.519) qualifica como “a não empregabilidade dos qualificados e elevação do nível de qualificação dos desempregados" faz com que os "herdeiros" desta classe se vejam de posse de diplomas que não garantem seu nível de vida, especialmente no tocante aos egressos das faculdades de comunicação, artes e afins. Some-se a isso a crise da indústria fonográfica e o recrudescimento dos empregos formais no âmbito da produção de conteúdo cultural à época da disseminação da Internet. Por outro lado, mas como parte do mesmo conjunto de condicionantes, o aquecimento da economia brasileira e o baixo índice de desemprego oficial que marcaram a primeira década dos anos 2000 no Brasil consentiam uma autoconfiança empreendedora desses jovens. Diante disso, jornalistas, designers, músicos, escritores, fotógrafos, entre outras profissões ditas "criativas", passam a se organizar coletivamente na tentativa de viverem de seus ofícios.

Condizente com esse contexto mais amplo, no seio desses coletivos, seus membros reeditam as representações históricas do artista, aquele que cria arte por amor e vocação e não por dinheiro. Professando a não diferenciação entre trabalho e lazer, ao mesmo tempo em que evocam o caráter "alternativo" das iniciativas (como, por exemplo, a coabitação e o uso de moedas paralelas), os jovens que trabalham nos coletivos afirmam constantemente o empreendedorismo como valor. A precariedade é transformada retoricamente em virtude (BENTES, 2012). A intermitência da atividade é transmutada em liberdade, as múltiplas jornadas e o acúmulo de funções são vividas e/ou apresentadas como flexibilidade ou como a habilidade a multitarefas. A divisão do local do trabalho se transforma em "hotdesking". O trabalhar a partir do quarto na casa 
${ }^{10}$ Para mais detalhes, consultar trabalhos já citados e discriminados nas referências ao final do texto. Além disso, como o modo de funcionamento de tais coletivos despertam polêmicas, é interessante acessar o dossiê sobre o ema organizado pelo Coletivo Passa tema organizado pelo Coletivo Passa Palavra (fonte:
http://passapalavra.info/2014/05/95606).

http.//passapalavra.info/2014/05/95606).

${ }^{11}$ Uma visita ao site do Fora do Eixo também pode ser, nesse sentido, esclarecedora:

http://foradoeixo.org.br/2015/03/03/calu nia-requentada/ Acesso em 17/06/2015.

${ }_{12}$ Assim que Juca Ferreira assume o MinC em 2015, Bentes foi chamada a assumir a Secretária da Cidadania e da Diversidade do Ministerio da Cultura, fato de que pode ser tomado como um claro exemplo das relações atuais entre as redes e coletivos e o poder público.

${ }^{13}$ A autora analisa o recente avanço das igrejas neopentecostais nas periferias do igrejas neopentecostais nas periferias do Brasil. Em alguns aspectos fundamentais, a organização e $\quad \mathrm{o}$ funcionamento dessas igrejas parecem apresentar afinidades eletivas com os coletivos em análise, mas o paralelo não poderá ser desenvolvido no escopo desse texto. dos pais ou da "república" se torna "homedesking" e "flexitime". A luta por recursos é apresentada como "captação", "funding”. A ajuda financeira de parentes e amigos é tida por "crowdfunding"... e assim por diante ${ }^{10}$. Assim, por um lado, o funcionamento interno de tais coletivos parece estabelecer dinâmicas similares às experiências do que Pierre Dardot e Christian Laval (2014) chamam de "comuns". A fala a seguir serve como exemplo:

Primeiro, como é um processo coletivo, qualquer pessoa que chega tem acesso a uma série de bens coletivos. A destinação de seus pertences para o uso de todos enquanto se está em uma Casa é um ato livre. Além disso, muitas pessoas chegam sem nada e, a partir do envolvimento na dinâmica colaborativa, recebem bens materiais e equipamentos para desempenhar suas atividades.

Por outro lado, nos discursos e nas práticas, eles apresentam similaridades com o mundo corporativo à época da acumulação flexível. Seu funcionamento interno parece estimular a adaptação, a concorrência e a corrida pela performance próprias à "subjetividade neoliberal" (DARDOT e LAVAL, 2010). Em concorrência com outras organizações, eles assumem a dinâmica da competição por recursos escassos, própria à concepção darwinista de sociedade que marca a "nova razão do mundo".

Sobre si mesmos, afirmam ter superado a "era do rancor", que, segundo seus detratores, em geral marxistas, seria o nome que dariam à noção de luta de classes (ARGÜELES, 2012). A adaptação é a regra. Segundo Ivana Bentes, professora da UFRJ e entusiasta e apoiadora da rede Fora do Eixo ${ }^{12}$, "não é só o capitalismo financeiro que funciona em fluxo e em rede, veloz e dinâmico. As novas lutas e resistências passam por essas mesmas estratégias". Ela afirma ainda que os coletivos, as redes e as "marchas" estariam na "base de um novo ativismo contemporâneo, a emergência do precariado cognitivo, [...] da percepção que o sistema trabalhista fordista e previdenciário não dão mais conta da dinâmica de ocupações livres (mesmo que frágeis e sem segurança) no capitalismo de informação" (apud ARGÜELES, 2012). Se Foucault, e, em sua esteira, Boltanski e Chiapello, estão certos ao sugerir que a resistência segue a lógica do poder a que resiste, também é verdade que a resistência, nesse caso, se parece bastante com a adaptação. $\mathrm{O}$ ativista parece se confundir com o "pró-ativo".

Ao discutir um assunto diferente do que temos em mira no presente texto ${ }^{13}$, Mariana Cortes $(2001,2014)$ contribui para nossa discussão na medida em que descreve bem o ocaso da política como resistência em tempos neoliberais. Para ela,

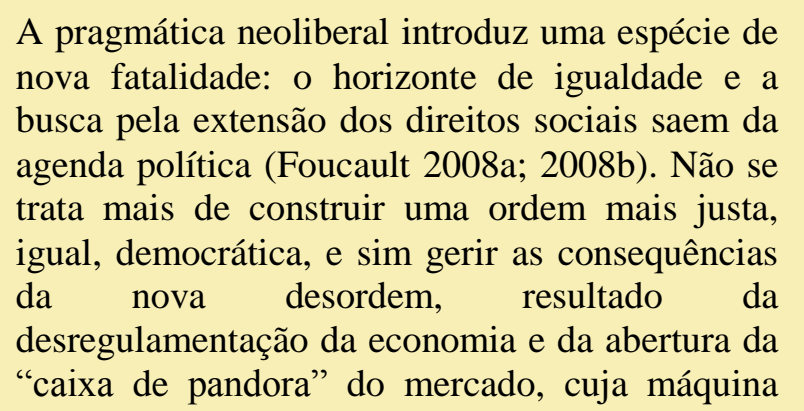


14 Sobre isso, consultar André Azevedo Fonseca op cit milagrosa do capital financeiro - que nos seduz com a fórmula fantasmagórica do dinheiro que procria dinheiro -, deixa no seu rastro milhares de "vidas desperdiçadas" (Bauman 2005) incapazes de acompanhar o frenesi da aceleração permanente e da mobilização total. A desigualdade, a pobreza, a violência, não serão eliminados ou concretamente combatidos, mas geridos. Gerir a desordem ou, nos termos de Chico de Oliveira (2003), "administrar a exceção". Com a instituição do novo "princípio gestionário" (Telles 2010), a exceção - que antes constituía os avatares do atraso a serem superados pela realização plena das promessas da modernidade - torna-se a regra. (CORTES, 2014 p. 35).

Assim, no contexto em que o futuro parece interditado, proibido - l'avenir semble interdit, afirmam Dardot e Laval (2014) ao iniciarem sua busca pelo comum como princípio político oposto à organização neoliberal do mundo -, tanto no que diz respeito aos modos de articulação política quanto no que concerne ao funcionamento econômico, estamos em face de uma mesma formação discursiva. Trata-se de conceber a vida, a sociedade, o mundo, como algo gerenciável com base no princípio da concorrência. A subjetividade neoliberal pensa a vida como empreendimento e como matéria a ser gerida. De acordo com Dardot e Laval (2010), essa subjetividade e essa filosofia se colocam em situações de não-mercado ou quase-mercado, como o Estado e a família. Se como (anti)princípio de organização da vida comum, países, cidades, empresas e indivíduos concorrem entre si, a lógica da concorrência, da adaptação e da sobrevivência dá o tom em situações que não seriam de mercado propriamente.

Pelo que foi exposto acima, poderíamos pensar nessa chave as redes e coletivos que se colocam entre o Estado e o Mercado, ao mesmo tempo negando e integrando ambos. Na base dessa formação discursiva, há o autoelogio do sujeito, do sujeito- indivíduo, do sujeito-líder, do sujeito-grupo. Como se trata de gerir-se enquanto subjetividade em concorrência, o autoelogio surge como tentativa da produção do valor de si e do si como valor. A produção do si como valor se liga à ideia de performance em avaliação constante. Em tempos de "capital humano" e de "egocard"14, no âmbito dos coletivos o discurso da colaboração se emaranha com estratégias de fortalecimento do indivíduo-grupal em concorrência com outros.

Enquanto os mesmos Dardot e Laval (2014) buscam no que chamam de "comum" sinais de falência dessa lógica, por saber que o princípio da concorrência é a- social, a análise do funcionamento e da atuação desses grupos revela que, neles, a colaboração não se apresenta como um fim em si, mas como um meio para aumentar o valor de si como coletivo-indivíduo com vistas a galgar posições concorrenciais. Parece tratar-se de meios alternativos para fins convencionais, o que é coerente com a subjetividade neoliberal, subjetividade que tem por mote a adaptação, que se proclama "pósrancor", isto é, pós-contradição, pós-conflito e mesmo pós-política da maneira como a transformação política foi concebida pela 
tradição materialista-dialética. É nesse contexto que se argumenta que "a associação acrítica ao aparelho de Estado e à lógica empresarial são operações comuns em movimentos socioculturais alimentados por certos esquemas teóricos pós-marxistas e pósmodernos, como é o caso do FdE" (ARGÜELES, 2013).

A concepção de mundo neoliberal pensa a sociedade como natureza. No léxico darwinista que tem marcado o nosso tempo, os mais fortes sobrevivem, e o fazem porque conseguem se adaptar. Ganham os onívoros, os ornitorrincos, os que conseguem ao mesmo tempo se nutrir do Estado e operar como o mais flexível dos mercados; ou, ainda, aqueles que conseguem se infiltrar em outros organismos.

Na conjuntura em que o termo resistência perde o sentido de contestação ou antagonismo para significar resiliência, fazer a crítica apenas àqueles que buscam se adaptar à selva darwinista seria reducionista. Tal crítica é importante na medida em que ela desmistifica muito da retórica que fundamenta a postura "sobreviventista" que se proclama alternativa, colocando as relações sociais mais às claras. Se tal postura admitir que é objetivamente interessada - o que não é evidente, como mostramos mais acima -, ela pode alimentar a política, ao menos em sua concepção de disputa de interesses. Aliás, pelo bem ou pelo mal, ela pode inclusive acessar a política institucional, imiscuir- se nela e buscar pautá-la, como tem ocorrido recentemente no Brasil. Mas ela pode se também a negação da política ao tentar adaptar-se a qualquer custo. Diferente do mundo natural, no mundo social adaptar-se é quase sempre o oposto de resistir.

Apresentado como prenúncio de novos tempos, o "sobreviventismo" é o corolário de nossa época. Nesse sentido, ele reproduz e revela as contradições do presente histórico. Enquanto a discussão específica acerca do potencial político das redes e coletivos permanece aberta, é mais terminante o fato mais amplo de que essa postura adaptativa é coerente com o nosso momento histórico, em que tanto Estado quanto Mercado concebem a cultura antes como um serviço do que como um direito, antes como um recurso do que como um fim.

\section{Referências}

ANDRADE, Daniel Pereira. Paixões, sentimentos morais e emoções. Uma história do poder emocional sobre o homem econômico. Tese (Doutorado - FFLCH-USP), 2011.

ANTUNES, Ricardo; BRAGA, Ruy. Infoproletários: degradação real do trabalho virtual. São Paulo, Boitempo: 2009.

ARGUELES, Régis. "Fora do Eixo", mas dentro da máquina. Disponível em: 〈http://blogconvergencia.org/?p=1660〉. Acesso em: 9 de agosto de 2013 .

ARGUELES, Régis. O pós-rancor e o velho Estado: uma crítica amorosa à política do Fora do Eixo. Disponível em $<$ http://passapalavra.info/2012/02/51886> Acesso em: 2 de fevereiro de 2012

BENTES, Ivana. Redes Colaborativas e Precariado Produtivo. In: Periferia, Volume 1. Número 1, 2012. BOLTANSKI, Luc. e 
CHIAPELLO, Eve. Le nouvel esprit du capitalisme. Paris: Gallimard, 1999

BOURDIEU, Pierre. As regras da arte. São Paulo: Companhia das Letras, 1996.

Le néo-liberalisme, utopie (en voie de réalisation) d'une exploitation sans limites. In: Contre-feux. Propos pour servir à la résistance contre l'invasion néo-liberale. Paris: Liber, 1998.

Les structures sociales de l'économie. Paris: Seuil, 2000.

BOURDIEU, Pierre; PASSERON, Jean Claude. A reprodução. Elementos para uma teoria do sistema de ensino. Rio de Janeiro: Francisco Alves, 1992.

CASTEL, Robert. Metamorfoses da questão social: uma crônica do salário. Petrópolis, RJ: Vozes, 1998.

CÔRTES, Mariana Magalhães Pinto. A configuração flexível da expansão neopentecostal na sociedade brasileira contemporânea. In XI Congresso Luso-Afro- Brasileiro de Ciências Sociais Diversidades e (Des)Igualdades, 2011, Salvador. Anais eletrônicos do XI Congresso Luso-Afro-Brasileiro de Ciências Sociais Diversidades e (Des) Igualdades, 2011.

CÔRTES, Mariana Magalhães Pinto. Mercado pentecostal de pregações e testemunhos: formas de gestão do sofrimento. Religião e Sociedade, Rio de Janeiro, 34(2): 184-209, 2014.

DARDOT, Pierre; LAVAL, Christian. La nouvelle raison du monde. Essai sur la société neoliberale. Paris: La Dévouverte, 2010

DARDOT, Pierre; LAVAL, Christian. Commun. Essai sur la révolution au XXI siècle. Paris: La Dévouverte, 2014

EAGLETON, TERRY. A idéia de cultura. São Paulo: Editora UNESP, 2005.

FREDERICO, Celso. Da periferia ao centro: cultura e política em tempos pós- modernos. Estudos Avançados. 27 (79), 2013.
FONSECA, André Azevedo da. O valor do "egocard": afetividade e violência simbólica na rede Fora do Eixo. Revista FAMECOS. Porto Alegre, v. 22, n. 1, p. 94-119, jan.-mar. 2015.

FORA do Eixo, dentro do MinC. Folha de São Paulo, Ilustrada, 12 de janeiro de 2015 .

GAY, Peter. Modernismo: O fascínio da heresia. São Paulo: Companhia das Letras, 2009.

GOMBRICH, Ernst Hans. A história da arte. Rio de Janeiro: LCT, 2012

GORZ, Andre. O Imaterial: conhecimento, valor e capital. São Paulo: Annablume, 2005

HARVEY, David. A Condição pós-moderna. São Paulo, Loyola 1992

Loyola, 2008.

Neoliberalismo: História e Implicações. São Paulo

HELLER, Nathan. Sorriso de monge, carteira de yuppie. Como pensa a nova geração de empreendedores do mundo tecnológico, Revista Piaú, Edição 88, Janeiro de 2014. Disponível em: $<$ http://revistapiaui.estadao.com.br/edicao-88/carta-de-sao-

francisco/sorriso-de-monge-carteira-de-yuppie. $>$. Acesso em $16 / 03 / 2014$

IANNI, Octavio. Teorias da Globalização. Rio de Janeiro: Civilização Brasileira, 2006

JAMESON, F. Pós-Modernismo: a lógica social do capitalismo tardio. 2 ed. São Paulo: Ática, 2004.

LÓPEZ-RUIZ, O. Os executivos das transnacionais e o espírito do capitalismo. Capital humano e empreendedorismo como valores sociais. Rio de Janeiro: Azougue Editorial, 2007.

LÖWY, Michel. O romantismo revolucionário dos movimentos de maio. Margem Esquerda, nº11, São Paulo, 2008

MARX, Karl. O Capital. Livro I. São Paulo: Boitempo, 2013. 
MOULIN, Raymonde. Le marché de l'art. Mondialisation et nouvelles technologies, Paris, Flammarion, 2003.

NICOLAU NETTO, Michel. Quanto Custa o Gratuito? Problematizações sobre os novos modos de negócios na música. ArtCultura, Uberlândia, v. 10, n. 16, p. 141- 142 155, jan.-jun 2008

NICOLAU NETTO, M. O Discurso da Diversidade: a Definição da Diferença a partir da World Music. Tese (Doutorado - IFCHUNICAMP), 2012.

OLIVEIRA, Francisco. Crítica à razão dualista/O ornitorrinco. São Paulo: Boitempo, 2003.

ORTIZ, Renato. Mundialização e cultura. São Paulo: Brasiliense, 1994

PRADO JR., Caio. Formação do Brasil contemporâneo. São Paulo: Companhia das Letras, 1991

RIFKIN, Jeremy. A Era do Acesso. São Paulo: Makron Books, 2000.

SAVAZONI, Rodrigo Tarchiani. Redes político-culturais e ativismo digital: o caso do circuito Fora do Eixo. Dissertação (Mestrado - Universidade Federal do ABC), 2013.

SENNET, Richard. A corrosão do caráter: as conseqüências pessoais do trabalho no novo capitalismo. Rio de Janeiro: Record, 2004.

SINGER, André. Os sentidos do Lulismo: reforma gradual e pacto conservador. São Paulo, Companhia das Letras, 2012.

SOUZA, Jessé. Os batalhadores brasileiros: nova classe média ou nova classe trabalhadora? Belo Horizonte: Editora UFMG, 2012.

THOMPSON, Don. O tubarão de 12 milhões de dólares: a curiosa economia da arte contemporânea. São Paulo: BEI, 2012.

WARNKE, Martin. O artista da corte. Os antecedentes dos artistas modernos. São Paulo: Edusp, 2001.
WEBER, Max. A ética protestante e o espírito do capitalismo. São Paulo: Companhia das Letras, 2004. 